\title{
LEGIBILITY
}

A major purpose of the Technical Information Center is to provide the broadest dissemination possible of information contained in DOE's Research and Development Reports to business, industry, the academic community, and federal, state and local governments.

Although a small portion of this report is not reproducible, it is being made available to expedite the availability of information on the research discussed herein. 
AUTHORis: $\quad$ Sarath Kumar Menon, MST-5

Thomas Roland Jervis, MST-3

Michael Nastasi, MST-7

Materials Science and Technology Division

Los Alamos National Laboratory

Los Alamos, New Mexico

SUEMITTED TO Proceedings of Material Research Society Symposium on Science and Technology of Rapidly Quenched Alloys, Boston, MA 12/2/86.

\title{
DISCLAIMER
}

\begin{abstract}
This report was prepared as an account of work sponsored by an agency of the United States Government. Neither the United States Government nor any agency thereof, nur uny of their employees, makes any warranty, express or implied, or assumes any legal liability or responsibility for the accuracy, completeness, or usefulness of any information, apparatus, product, or precess disclosed, of represents that its uss would not infringe privately owned rights Refer. ence herein 60 any specific commercial product, pricess, or service by trade name. Irademark, munufacturer. or otherwise does not necessarily constitute or imply its endorsement, recom. mendation, or favoring by the United Stules Ciovernment or uny agency thereof. The views and upinions of authors expressed herein do not necessurily state or reflect those of the United states (jovernment or any arency the reof.
\end{abstract}




\section{MICKOSTRUCTURE OF METASTABLE METALLIC ALLOY FILMS PRODUCED BY LASER BREAKDOWN CHEMICAL VAPOR DEPOSITION AND ION IMPLANTATION}

S. K. MENON*, T. R. JERVIS, and M. NASTASI

Materials Science and Technology Division, Mailstop E549, Los Alamos Naticnal Laboratory, Los Alamos, NM 87545, \#Present address: Naval Chemical \& Netallurgical Laboratory, Naval Dockyard, Tiger Gate, Bombay 400023, India

\section{ABSTRACT}

Trin films produced by laser breakdown chemical vapor deposition from nickel and iron carbonyls and by implanting $\mathrm{Ni}$ foils with varying levels of $C$ nàve been characterizea by transmission electron microscopy. Decomposition of $\left.\mathrm{Ni}_{(\mathrm{CC}}\right)_{4}$ produces polycrystalline films of $\mathrm{fCC} \mathrm{Ni}$ and metastable ordered nexacunal $\mathrm{Ni}_{3} \mathrm{C}$. This metastable phase is identical to that produced by gas carburization, rapid soliaification of $\mathrm{Ni}-\mathrm{C}$ melts, and ion implantation of $\mathrm{C}$ into $\mathrm{Ni}$ at low concentrations. Increasing the $\mathrm{H}_{2}$ content in the gas mixture during laser deposition reduces the grain size of the films significartly with grain sizes smaller than 10 nanometers produced. Laser uecomposition of $\mathrm{Fe}(\mathrm{CO})_{5}$ produces films with islands of fcc garma-Fe and tinely dispersed metastable $\mathrm{Fe}_{3} \mathrm{C}$ (Cementite). In addition, the ferrous oxioes $\mathrm{Fe}_{2} \mathrm{O}_{3}$ and $\mathrm{Fe}_{3} \mathrm{O}_{4}$ were found in these samples. Implants of $\mathrm{C}$ ilito pure $\mathrm{Ni}$ foils at $770 \mathrm{~K}$ and at a concentration of 35 at.\% produced anorohous layers. Implants at the same dose at room iemperature did not proouce amorplious layers.

\section{INTROLULTION}

Recently, a new tecnnique for the prefaration of thin films by gas pliuse pyrolysis of metal bearing gas mixtures has been developed[1,2]. The technique utilizes laser dielectric breakdowr of gas phase precursors to inauce the deposition of metallic films on an unheated substrate. During the process, oecoriposition and deposition on the substrate occur in a short tinie $(<2 \mathrm{msec})$ and hence the entire process is expected to yield ich-equiliuriur. structures. In tris work, thin films produced ty laser ureakoown chenical vapor deposition (LBCVO) from $\mathrm{Ni}$ and $\mathrm{Fe}$ carbonyls have UEell examintec ano tieir structure characterized with emphas is on identifying the phases present. Comparable structures in the $\mathrm{Ni}-\mathrm{C}$ system were also proouceo by ion inulantation. In a sample implanted at the highest dose (corresuonoing to a C concentration of 35 at.q) at $770 \mathrm{~K}$, an amorphous surface layer was formed, indicating that diffusion kinetics limit the furliation of the amoruhous phase.

\section{EXPEKIMENT}

Thin filmis were formed by laser deposition process in which gas phase cllemical reictions are initiated in a flowing gas mixture[2]. Dielectric breakdown in the mixture caused by the focused beam of a pulsed $\mathrm{CO}_{2}$ laser creates a plasnia region a short distance above the substrate. the gas mixture is orinarilv ar with at most 3\%. conirre nacse and un in ana u. 
when this is a halide. The Ar buffers the reacting species and enhances dielectric breakoown. The substrate is heated only to insure volatility of the source gas $(T<350 \mathrm{OK}$ ) and there is no direct interaction between the plasma itseif and the deposited film so that there is little surface energy available to the depositing materials. This results in direct deposition of metastable forms, even when sufficient rearrangement occurs to form continuous metaliic films. For the convenience of microstructural characterization, thin films were deposited on $\mathrm{NaCl}$ substrates and the films floatec onto $3 \mathrm{ani} \mathrm{Cu}$ grids. Implants of $\mathrm{C}$ into $\mathrm{Ni}$ foils were performed to result in surface layers with $C$ concentrations of 17, 25, and 35 at. 8 . All specinens were examined in a Phillips $400 \mathrm{~T}$ transmission electron microscope operating at $120 \mathrm{KV}$.

\section{RESULTS AND UISCUSSION}

Thin films proauced by LBCVD from $\mathrm{Ni}$ and $\mathrm{Fe}$ carbonyls and the surface layers of implanted foils were examined by transmission electron microscopy. The results of the microstructural analysis will be presented and compared in the following sections.

Uecoriposition of Nickel Carbonyl, $\mathrm{Ni}(\mathrm{CO})_{4}$ :

A typical microstructure observed in the LBCVD $\mathrm{Ni}$ samples and the corresponding selecteo area diffraction (SAD) pattern are shown in Fig. 1. As can te seen in Fig. I(a), the samples produced by LBCVD of $\mathrm{Ni}^{(\mathrm{CO})} 4 \mathrm{4}$ are fine-grained (grain size $5 ., 5 \mathrm{~nm}$ ) polycrystalline films.
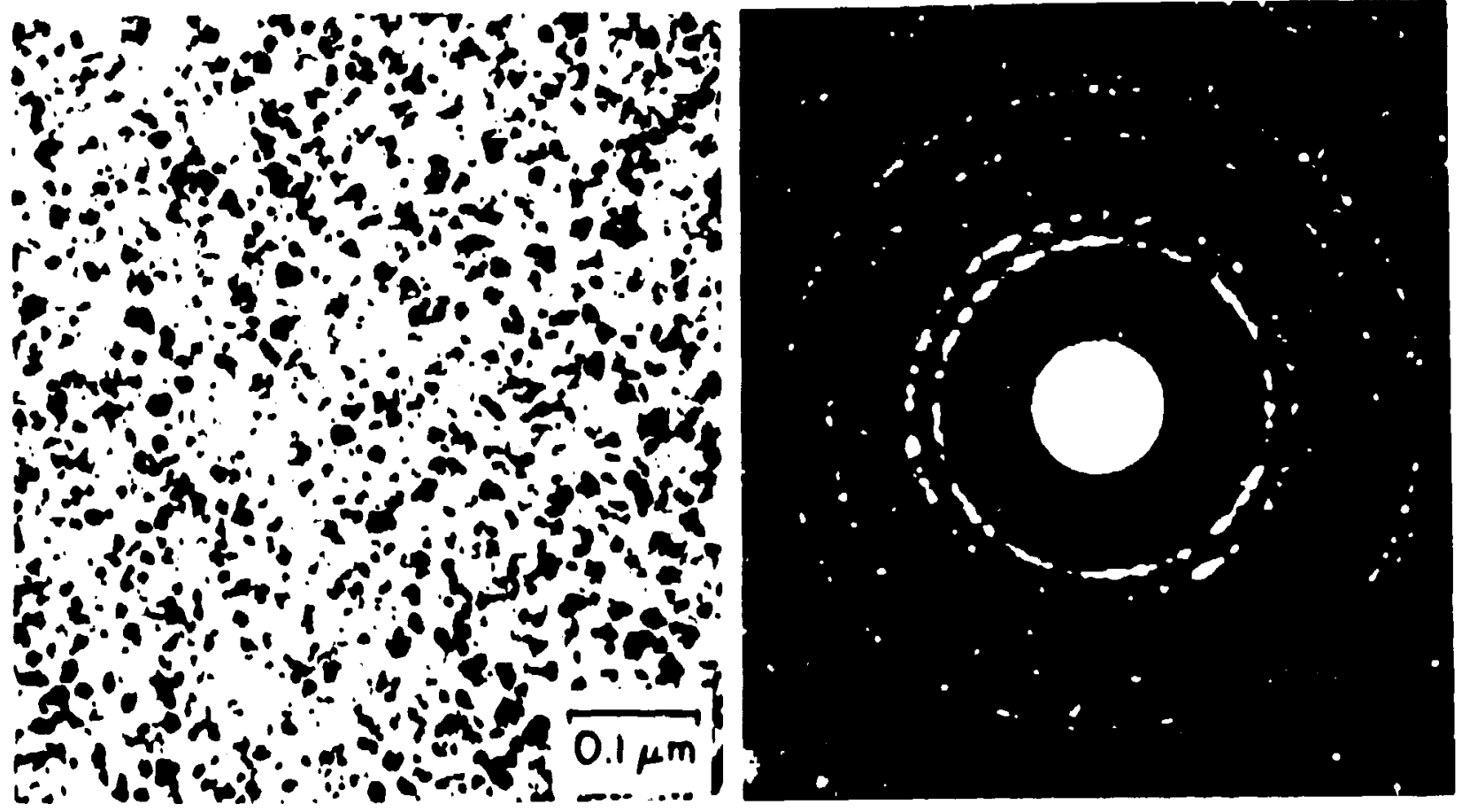

FiG. 1.la) Brightfiela micrograph lllustrating the fine grained film oepositeo by LBCVD from $\left.\mathrm{NI}_{(\mathrm{CO}}\right)_{4}$. (L) SAD pattern showing the presence of fCC Ni arid $\mathrm{NI}_{j} \mathrm{l}$. 
SAD patterns from these samples revealed diffraction spots arranged as nearly continuous rings as shown in Fig $l(b)$. Analysis of these diffraction patterns revealed that $\mathrm{fCC} \mathrm{Ni}$ and ordered $\mathrm{Ni} \mathrm{C}$ are present. Table I lists the unserved interplanar spacing as measured from the SAD patterns and the illoexing scheme. Since the SAD patterns showed many closely spaced rings, often quite weak in intensity, measurement of the d-spacings was aided by microaensitolueter traces of the diffraction patterns. The indices for the wizl phase correspond to an ordered hexagonal lattice and matches very well with the structure described by Nagakura[3,1] who obtained this phase by gas carburization of thin $\mathrm{Ni}$ films deposited on $\mathrm{NaCl}$ crystals. The lattice constante found here are $a=0.455 \mathrm{~nm}$ and $c=1.29 \mathrm{~nm}$. This phase las also beel obtainea in $\mathrm{Ni}-\mathrm{C}$ alloys by liquid phase quenching[5]. The lattice parameter of the $\mathrm{fcc}$ phase was estimated from the electron aiftraction aata to be $0.355 \mathrm{nr}$ indicating a considerable increase from that of pure $\mathrm{Ni}(\mathrm{a}=0.35238 \mathrm{~nm})[6]$. The maximum equilibrium solid solubility of $l$ in $\mathrm{Ni}$ is reported to be 2.7 at. $2[7-9]$ and hence it is clear that the $\angle B C V D$ process leads to a considerable degree of supersaturation in the $f C C$ phase. A rough estimate of the carbon concentration in the fcc phase can be obtainea from the relationship $\mathrm{a}(\mathrm{nm})=0.35240+0.0008 \times$ at. $\% \mathrm{C}$ as repurteo by Ruhl ano Colienili]. Accordingly, the fcc phase produced by '. BCVO contains about 7.7 at. : $C$ in solid solution. This is consistent with ilie metastable equilibrium oiagram obtained by Ershova et. al.[9] which inoicates a maximuri $\mathrm{C}$ solucility of 7.4 at.\% in the $\mathrm{Ni}-\mathrm{Ni}_{3} \mathrm{C}$ phase ai agran. Auger spectroscopy analys is indicates from $8-25$ at.2 $C$ in $L B C V D$ fiinis. A very rough estimate based on the lever rule indicates that the salilies analysed contain about $14 \%$ by volume of the $\mathrm{Ni}_{3} \mathrm{C}$ phase. Darkfield microscopy experiments showed that the samples were composed of entire yrails of the carbide phase.

TABLE I

Phases Present in Ni Films

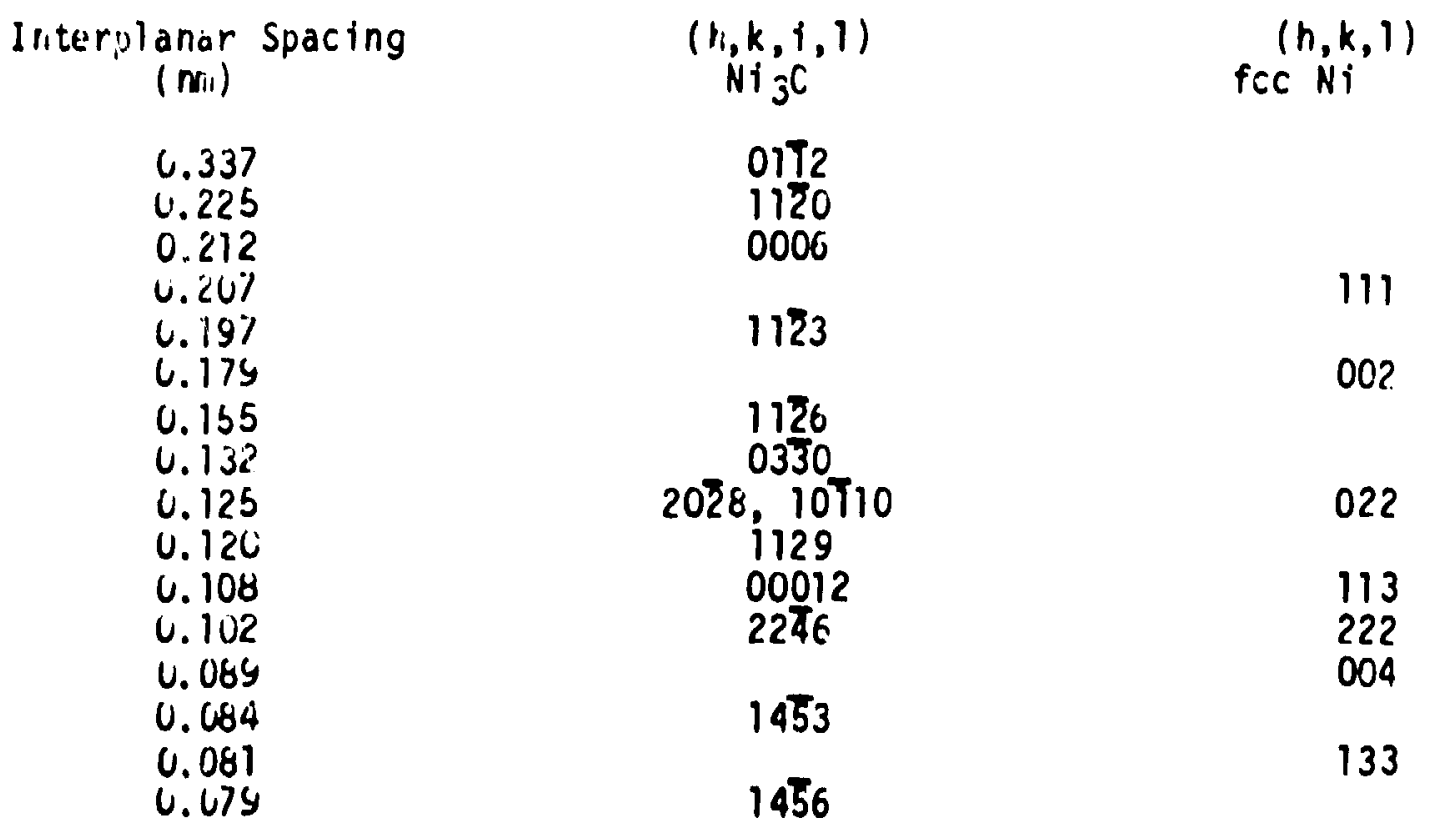



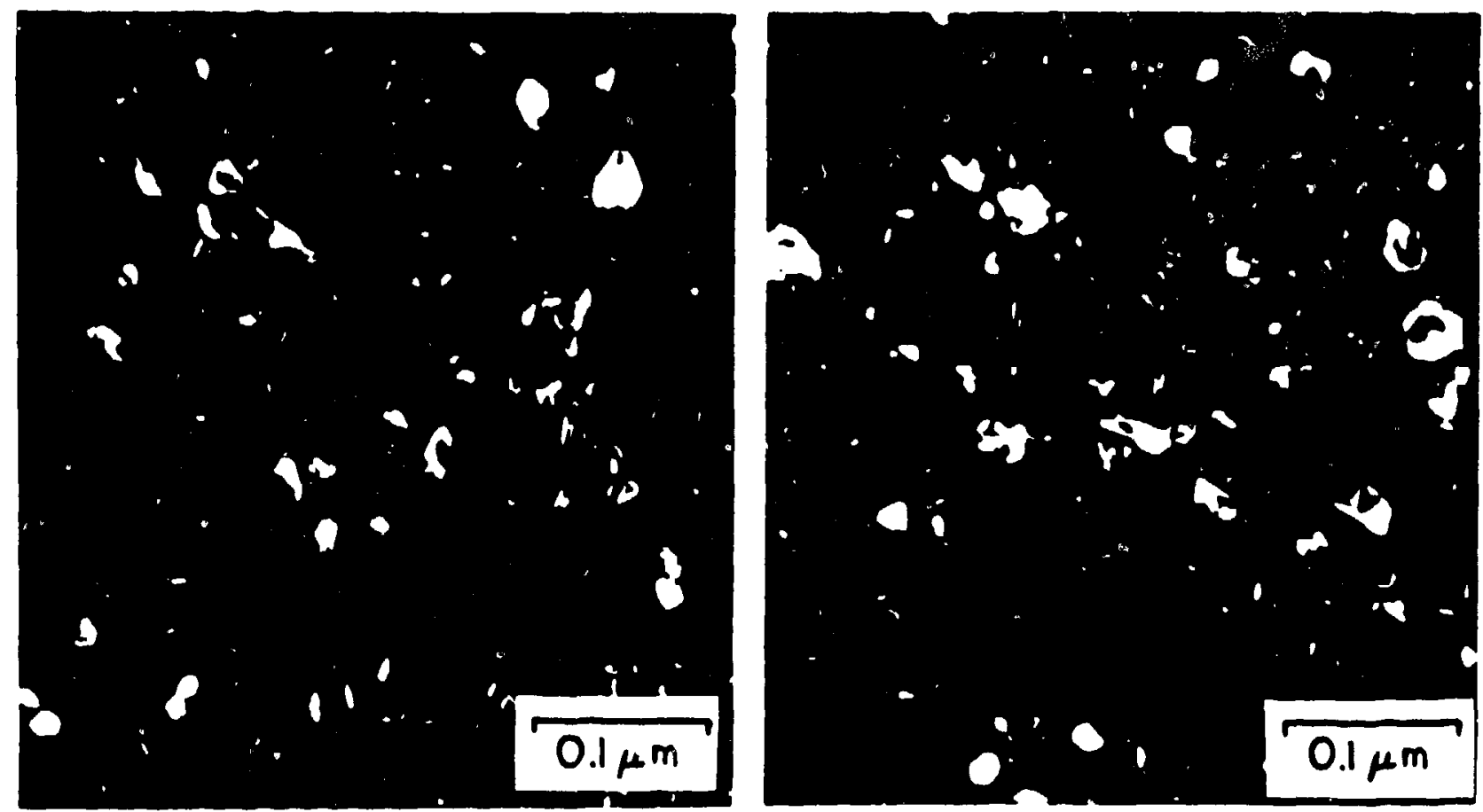

FIGURE 2. Darkfield micrographs of $\mathrm{Ni}-\mathrm{C}$ film obtained from two positions on the same diffraction ring.

Fig. 2 shows two dark field micrographs from the same area which were obtained by enclosing a large number of diffraction spots within the objective aperture. The two darkfielc micrographs shown in Fig 2 were obtained from the same area of the specimen but by positioning the objective aperture at two different positions along the diffraction ring. It is evioent from Table I that several d-spacings corresponding to $\mathrm{Ni}_{3} \mathrm{C}$ and $\mathrm{fcc}$ in a are very close and one cannot isolate the fcc Ni spots from the $\mathrm{Ni}_{3} \mathrm{C}$ spots in the SAD pattern. Dark field micrographs (similar to Fig. 2) obtuined from several portions of the diffraction ring failed to show any morphology other than equiaxed grains associated with either of the phases presellt in the films. Hence, we conclude that both the fCC $\mathrm{Ni}$ and $\mathrm{Ni} 3 \mathrm{C}$ yrains possess similar equiaxed morphology. These observacions suggest that both of these phases nucleated independently from the gas phase rather than forming from a supersaturated $\mathrm{fCC}$ solid solution which subsequently precipitated the Nigl phase.

Vecoliposition of iron carbonyl, $\mathrm{Fe}(\mathrm{CO})_{5}$ :

Fig. 3 illustrates a typical bright field micrograph and the corresponding SAD pattern obtained from thin films produced by LBCVD of $\mathrm{Fe}(\mathrm{l} U)_{3}$. As can be seen from $\mathrm{Fig} 3(\mathrm{a})$, the microstructure consists of islands of one phase in uniform dispersion of very fine precipitates. The structure appears to be much more complex than that cf the $\mathrm{Ni}$ fllms. Allalysis of the $S A D$ partern reveals the presence of $\mathrm{Fe}_{2} \mathrm{O}_{3}$ and $\mathrm{Fe}_{3} \mathrm{O}_{4}$ in audition to cementite ( $F e_{3} C$ ) and austenite (gamia). 

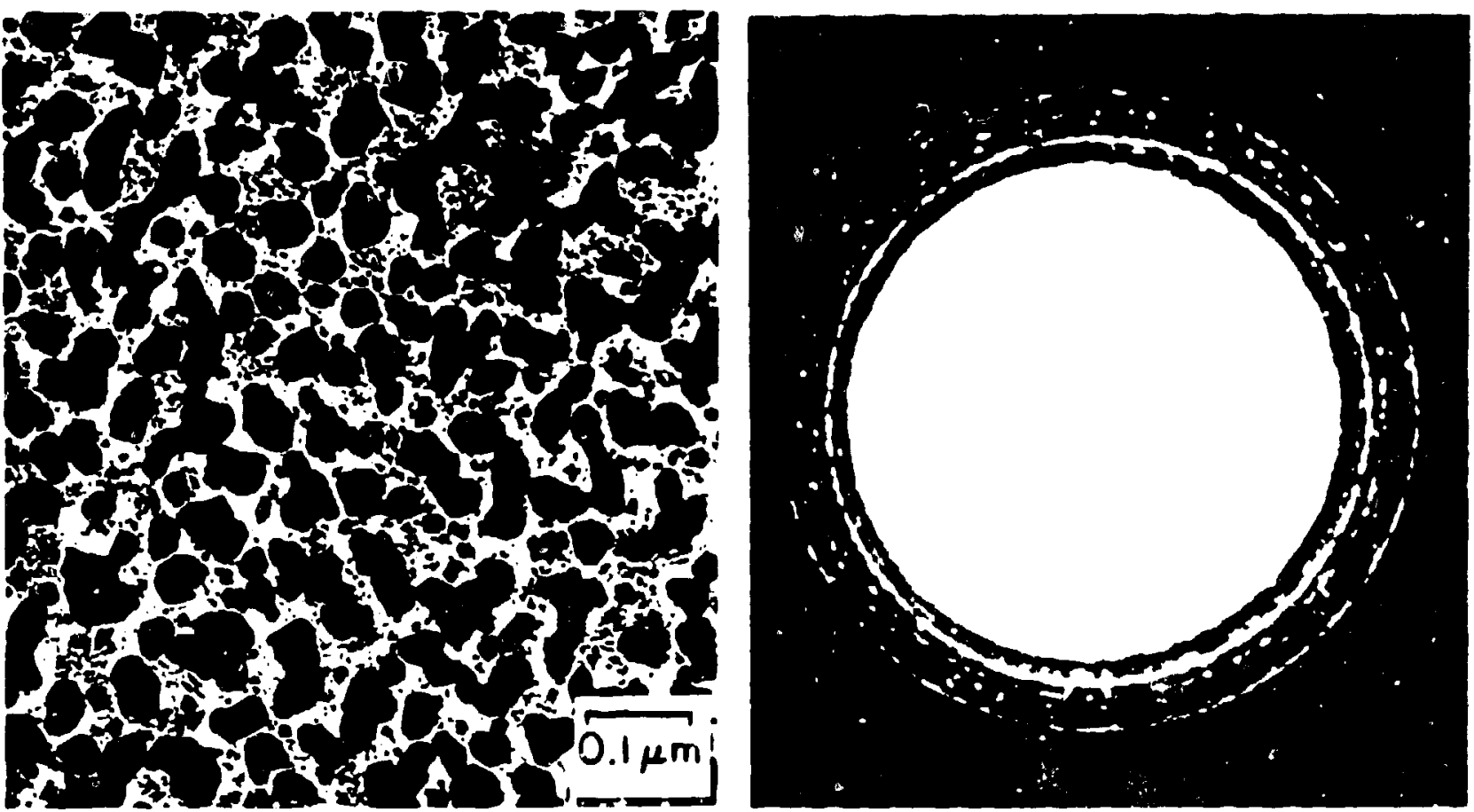

FIGURE 3.(a) Brightfield micrograph illustrating the film produced by LBCVD frori. $\mathrm{Fe}(\mathrm{CO})_{5}$. (D) SAD pattern showing the presence of multiple phases.

Table II shows a list of the observed d-spacings and the indexing scheme. It appears that both the oxides may simultaneously be present though the analysis is not unambiguous. The interes ing point to be noted is that austenite is stabilized ano no diffractiun spots could be associated with either of the bCC phases of iron. This finding is not really surprising since binary $F e-C$ austenite can indeec be stabilized at high $C$ concentrations since the martensite start temperature drops to temperatures below room temperature when the carbon content increases beyond $1.23 \mathrm{wt}$. q[11]. The lattice parameter of the gamma phase estimated from the data in Table II curresponds to $0.365 \mathrm{~nm}$. Based on the lattice parameter vs carbon concertration data reported by Roberts[12], this corresponds to a carbon conceritration of 2.32 wt. $\%(10$ at. $\%)$ which is slightly higher than the maximum solid solubility of carbon in binary Fe-C austenite reported in the FE-Fejc metastable equilibrium diagram[7].

TABLE II

Phases Present in Fe Films

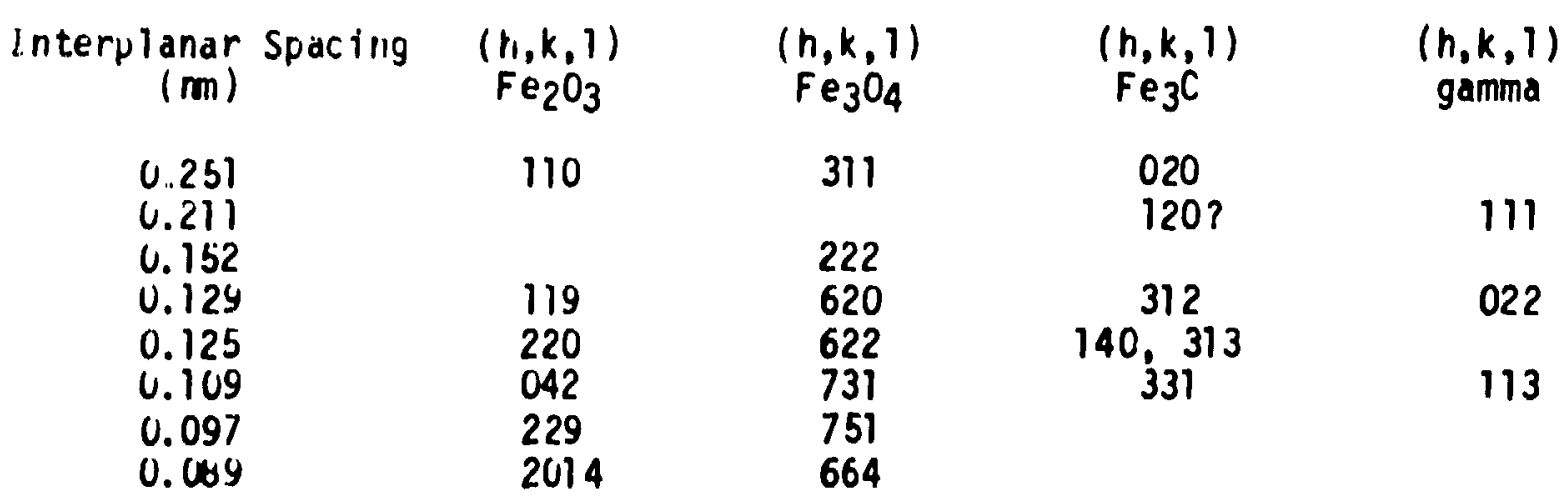


As mentioned before, the microstructure consisted of a distribution of very fine particles of $\mathrm{Fe}_{3} \mathrm{C}$ which are best seen in the dark field microyraphs shown in Fig. 4. Fig. 4(a) shows a dark field micrograph cotained mainly from the (ill)-gamma spots and shows the austentte grains clearly. Fig. 4(b) shows a bimodal distribution of particles with relatively larye austenite grains and very fine $(5 \mathrm{~nm})$ particles of cementite $\left(F_{j}(\mathrm{l})\right.$. The matrix is presumably a thin film of the oxides.
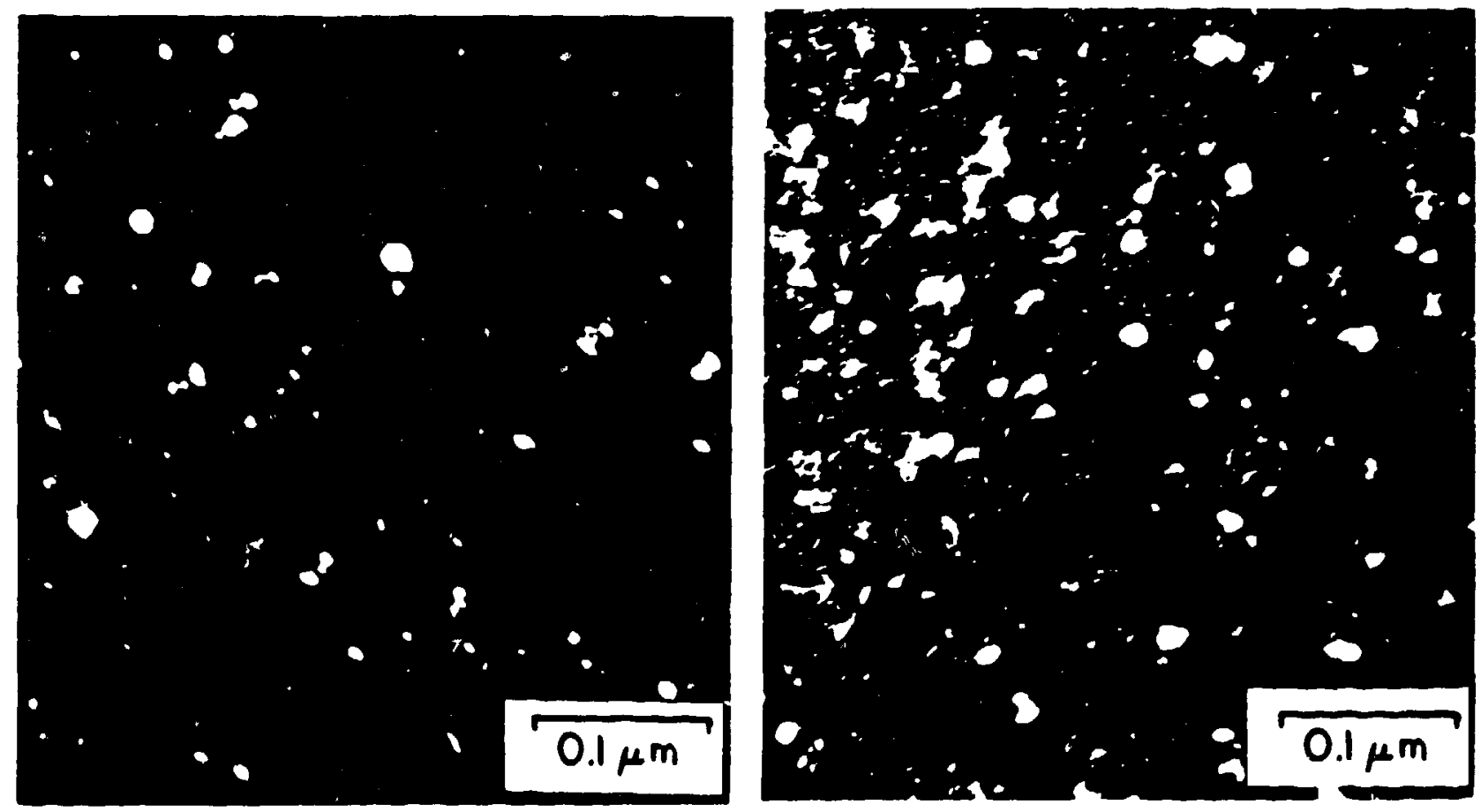

FIGUKE 4. Darkfield micrographs of Fe-C film showing size difference between austenite and ementite grains.

Ion Implantation of $C$ into Ni Foils:

Carbon ions were inplanted into pure $\mathrm{Ni}$ foils at an energy of $35 \mathrm{KeV}$, doses of $2.0,3.0$, and $4.2 \times 1077 / \mathrm{cm}^{2}$, and at $2.8 \times 10^{-6} \mathrm{~A} / \mathrm{cm}^{2}$. These implants resulted in $C$ concentrations in the surface layer of 17,25 , ario 35 at.\% as measured by Auger electron spectroscopy. Implants performed at the highest dose were made into substrates held both at room temperature anc at $770 \mathrm{~K}$. These foils were subsequently thinned from the back side and ion milled to produce samples for TEN anaiysis. At concentrations up to 35\%, mixed phase microcrystalline $\mathrm{Ni}$ and $\mathrm{Ni} 3 \mathrm{C}$ were formed. The $\mathrm{Ni}_{3} \mathrm{C}$ microstructure was identical to that found in the LBCVD, liquid quer,ched, and carburized sariples. The microstructure of the sample implanted at $770 \mathrm{~K}$ aiffered from the others in that an amorphous surface layer was formed. No aniorphous surface layer was observed in the sample implanted under the same conditions at room temperature.

viscussion:

The experimental results presented here indicate that decomposition of both $\mathrm{Ni}$ and $\mathrm{Fe}$ carbonyls results in the formation of a supersaturated fcc 
$\therefore$ In $\mathrm{Fe}-\mathrm{CL} 13]$ and $\mathrm{Ni}-\mathrm{C}[5]$ alloys that were liquid quenched. Gas carburization of $\mathrm{Ni}$ proouces $\mathrm{NizC}$ identical to that observed here, however, gas carburization of $\mathrm{Fe}$ is reported to produce cementite only above $6230 \mathrm{~K}$ while other carbides are formed at lower temperatures[14]. Again, ion implantation in $\mathrm{Ni}$ produced $\mathrm{Ni}_{3} \mathrm{C}$ with crystal structure identical to that founo here while $\mathrm{Fez} C$ has been reported to form after implantation of $C$ into pure Fel 15J. Gas carburization aliows for considerable atomic diffusion ano the proaucts fo:mea have presumably approached themodynamic equilibrium with the metastable phases observed present only due to sluggish kinetics. Liquia quenching and ion implantation do allow some atomic diffusion though very limited in comparison to carburization with the products presumably in a luetastable equilioriun state. This study shows that even a severe quench from the gas phase fails to completely stop the system from approaching its Eylilibrium structure. This indicates that the carbides $\mathrm{Ni}_{3} \mathrm{C}$ and $\mathrm{Fe}_{3} \mathrm{C}$ are associated with a very high thermodynamic driving force for their fornation even thoush both of these phases are metastable. The formation of an amorphous layer in the substrate held at low temperature indicates that altrough the saturated $\mathrm{Ni}-\mathrm{Ni}_{3} \mathrm{C}$ mixture is associated with a high thermodynamic driving force, a severe restriction of diffusion can result in the formation of an amorphous phase.

\section{ACKNOWLEDGEMENTS}

This work was carried out when one of the authors (SKM) was a Postdoctoral Feliow at the LOS Alamos National Laboratory. SKM gratefully acknowleayes the Director, Los Alamos National Laboratory, for granting the fellowship. We would like to thank R. Cordi for the Auger analysis and also acknowleaye the support of the U. S. Department of Energy under contract W-74U5-ENG-36.

\section{REFERENCES}

I. T. R. Jervis, J. Appl. Phys. 581400 (1985).

2. T. R. Jervis \& L. R. Newkirk, J. Mat. Res. I 420 (1986).

j. S. Nagakura, J. Phys. Soc. Jap. 12482 (1957).

4. S. liagakura, J. Phys. Soc. Jap. $\sqrt{3} 1005$ (1958).

2. S. K. Nishitani, K. N. Ishihara, R. O. Suzuki, \& P. H. Singu, J. Mat. Sci. Lett. $4 \& 72$ (1985).

o. J. b. Eaington, Electron Diffraction in the Electron Microscope, Mono,yraph 2 in Practical Electron Microscopy in Materials Science, $p$. 116, Phillips, Eindhoven, T975).

\%. Mi. Hansen, Constitution of Binary Alloys, McGraw Hill, New York (1958).

6. H. Ontani, M. Masebe, T. Nishizawa, Trans. I. S. J. J. 24857 (1984).

9. T. F. Ershova, D. S. Kanenetskaya, \& L. P. Il'ina, I IVV. Akad. Nauk. 'SSSR, Met. 4201 (1981).

1U. R. C. Ruhi Ta M. Cohen, Scripta Metall. 173 (1967).

11. W. Stevens \& A. G. Haynes, J. I. S. I. T83 349 (1956).

12. C. S. Roterts, Trans. AIME, 191203 (1953).

1s. F. H. Samuel, Zeit. Metallkde. 70792 (1985).

14. S. Nayakura, J. Phys. Soc. Jap. T4 186 (1959).

1j. D. M. Follstaedt \& J. A. Knapp. "Binary \& Ternary Amorphous Alloys of Ion Iliplanted Fe-Ti-c", To be Published in Mat. Res. Soc. Symp. Proc. 51. 